\title{
Respuesta tardía a la descalificación y crítica destructiva de dos profesores de Universidad que no toleran a quienes mantienen ideas y puntos de vista distintos a los suyos en la investigación y docencia de la Paleografía *
}

\author{
ÁNGEL RIESCO TERRERO
}

Lamento no haber podido responder a su debido tiempo al artículo publicado contra mí y contra el resto de los coautores de un manual universitario, al que después me referiré, en la revista italiana Scrittura e Civiltà por los profesores de Paleografía y Diplomática de la Universidad de Alcalá de Henares, los doctores don Antonio Castillo Gómez y don Carlos Sáez Sánchez. Circunstancias ajenas a mi voluntad me lo han impedido y esto justifica el calificativo de "respuesta tardía" que aparece en el título de mi contestación.

Tal vez alguno puede pensar que lo lógico hubiera sido escribir y responder en la misma revista que dio acogida a dicha crítica. Puedo asegurar que a estas alturas - el mencionado escrito se publicó en 1999- he dudado si merecía o no la pena dar cumplida respuesta a semejante crítica de descalificación. Sin embargo, me ha parecido desproporcionado recurrir a esa misma revista o a cualquier otra extranjera de tanto o más prestigio y difusión que Scrittura e Civiltà sencillamente porque el nudo gordiano de tal escrito, aparte de inconsistente y desproporcionado, lo considero intrascendente y de escaso rigor científico, algo así como el «mons parturiens murem" de los clásicos. Por eso he preferido que la polémica, que no pasa de casera, quede reducida al ámbito nacional, con el fin de evitar que otros especialistas pertenecientes a escuelas tanto italianas como francesas, austriacas, alemanas o inglesas se vean obligados a intervenir en asunto tan poco grato y de tan mal sabor académico.

* Este escrito se recibió en la redacción de la revista Espacio, Tiempo y Forma, solicitándose su inclusión en la Serie III. Historia Medieval. La dirección de la revista acordó su publicación, no haciéndose responsable de los contenidos que se vierten en el mismo. 
Bien venida sea la crítica objetiva, leal y constructiva de quienes con autoridad científico-académica pueden juzgar el valor de las aportaciones realizadas por cuantos nos dedicamos a la enseñanza superior y a la investigación en cualquier campo del saber. Este tipo de crítica, aparte de útil y positiva, resulta de todo punto necesaria como correctivo orientador y acicate imprescindible para el avance y el progreso de la ciencia y ampliación de la cultura.

Sin embargo, creo que ha llegado el momento de plantar cara y hacer frente a quienes en lugar de enseñar e investigar seriamente, contribuyendo así a la formación integral del alumnado y a la construcción del saber, se dedican a descalificar, fríamente y sin conocimiento de causa o por rabieta, la labor docente, investigadora y publicista de cuantos sienten la responsabilidad de la profesión y oficio que desempeñan dentro de la sociedad y, más concretamente, en la Universidad.

Adoptar a finales del siglo $x x$ una postura inquisitorial, al estilo medieval, con cuantos no siguen sumisamente la línea investigadora y publicista que, a toda costa, algunos tratan de imponer como única vía válida, para terminar despreciando como inservibles, anticuadas, puramente descriptivas y superficiales..., la labor y aportaciones de los que no secundan ni admiten su línea, cuando menos, me parece un peligroso atrevimiento rayando en la osadía y, sobre todo, una falta de respeto a la libertad de expresión, de cátedra e investigación y de pensamiento.

Recuerden, los que se aferran al arma de la descalificación, que el estudio, la verdad, el saber y la cultura son bienes de la humanidad no limitados a nadie, ni exclusivos de quienes, sin serlo, se erigen en jueces y maestros inapelables de los demás.

A este propósito viene a mi memoria una anécdota jurídica, repetida mil veces por uno de mis mejores profesores de Derecho Civil: Distingan ustedes - nos decía- entre la justicia y lo justo, porque no siempre el dictamen y la aplicación de la justicia concuerdan ni coinciden con lo que es justo. Tampoco la descalificación se compagina con el talante universitario y rara vez responde a la verdad.

Es penoso, pero en este caso necesario y conveniente, tener que responder en nombre propio y como catedrático de Ciencias y Técnicas Historiográficas de la U.C.M. y en el de once profesores más -pertenecientes a distintas Universidades de España, todos coautores de la obra colectiva, tipo manual universitario, Introducción a la Paleografía y Diplomática General. Madrid, Editorial Síntesis, 1999 - a la breve pero acerada e injusta crítica vertida especialmente contra mí, aunque también contra dicha obra y todos sus coautores, exceptuados, claro está, don Carlos Sáez Sánchez y 
don Antonio Castillo Gómez, profesores de Paleografía de la Universidad de Alcalá de Henares, sin los cuales el fracaso y descrédito del manual hubiera sido completo.

Dicha nota crítica, publicada en Scrittura e Civiltà, vol. XXIII, 1999, 439-443 gracias al mecenazgo del Doctor Armando Petrucci, lleva por título «La eliminación de lo social. A propósito del concepto y destino de la Paleografía".

Intentaré con la máxima concisión y objetividad posibles, responder a las acusaciones y aclarar algunos conceptos erróneos que, según los «descubridores de la nueva Paleografía», merezco yo y cuantos me siguen, por reducir dicha ciencia y saber a pura «taxonomía y descripción gráfica, de contenido empirista e inspiración positivista, desprovista de capital simbólico, cuyo objeto, la escritura, ha sido despojado (por todos nosotros) de la constante e irrenunciable vinculación entre ella y la sociedad" (a.c., p. 42).

Aunque en la portada del manual Introducción a la Paleografía... aparezco como "editor", en realidad no lo he sido; mi intervención -puedo demostrarlo- fue la de simple "coordinador", a ruego de la "promotora" de la obra, la Doctora Doña Ana Belén Sánchez Prieto, profesora titular de Escuela Universitaria, y de quienes a ella le encomendaron esta misión el Doctor José López Yepes y la propia Editorial Síntesis. Quede claro que no fui yo quien invitó a colaborar en esta obra a los profesores Castillo y Sáez y que el trabajo que se les encargó debía ceñirse -por razón de la naturaleza, objetivos y finalidad del manual- a exponer el concepto, definición método y técnicas de la Paleografía científica actual. Tras la lectura del capítulo elaborado por ambos profesores, el capítulo primero del manual, y sin entrar a juzgar si era bueno, mediano o malo, rogué a la Doctora Sánchez Prieto que se pusiera en contacto con sus respectivos autores para decirles que su trabajo no encajaba con el resto de las colaboraciones y menos con la finalidad del manual y, en consecuencia, que tenían las siguientes opciones: a) retirar su trabajo; b) retocarlo, si lo consideraban oportuno, conforme a las directrices que se les habían indicado y, en caso contrario, aceptar, si no respondian, y c) que el "coordinador" y la "promotora" hiciesen las correcciones oportunas o, bien, encomendasen a otro profesor cualificado y deseoso de colaborar, ese primer capítulo de la obra o volumen de conjunto.

Al no dar respuesta alguna los profesores de Alcalá, y con el deseo de complacer a la "promotora" y a la Editorial, que insistentemente reclamaban prontitud en la entrega de originales para no ralentizar la publicación, decidí redactar el breve apartado aclaratorio que figura dentro del mencionado capítulo 1. .9 con el título: «1.4 Conclusión», pp. 29-30, y que la Docto- 
ra Ana Belén Sánchez Prieto y la Editorial - no yo- colocaron al final de la parte expositiva, si bien antes del cuadro final (o.c., p.31). A esta nota aclaratoria que yo firmé, dirigida al alumnado y posibles lectores, y a la omisión del término "social», retirado del título de su colaboración, lo llaman los profesores de Alcalá "paratexto", "manipulación", "apropiación indebida" y otras lindezas; todo lo cual es falso una vez hechas las advertencias previas a que he aludido más arriba.

La Editorial Síntesis nos exigió también la reducción de números de páginas de todos y cada uno de los artículos, exigencia que tuvimos que observar, aunque esto implicaba limitaciones y cambios totalmente imprevistos e, igualmente, la parquedad en las notas dentro del texto y que la bibliografía principal y más representativa del conjunto de temas expuestos se colocara, no a pie de página y en cada capítulo, sino en un apéndice bibliográfico al final de la obra, evitando las repeticiones.

Estas y otras imposiciones editoriales y tipográficas afectaron por igual a todos los coautores y, en consecuencia, no fue la colaboración de los profesores Sáez y Castillo la única que sufrió alteraciones.

Ninguno de los numerosos colaboradores de la obra, excepto los dos mencionados, se ha llevado las manos a la cabeza, ni ha tenido que recurrir "a la generosidad" del Doctor Armando Petrucci (a.c., p. 442) para despacharse con tan poco estilo y descalificaciones tan zafias no sólo contra mi sino también contra ese nutrido grupo de profesores universitarios, al menos, tan dignos y cualificados como sus acusadores. Sin profundizar demasiado en el análisis de semejante conducta - cuando menos irreflexiva y pueril- me permito utilizar una expresión cervantina aclaratoria.

La crítica vertida en la revista Scrittura e Civiltà responde sencillamente a que, como dice Cervantes en la primera parte del Quijote (cap. 48), los dos profesores de Paleografía de la Universidad de Alcalá están tan asidos e encorporados a su parecer, que no hay razón, ni evidencia, que dél los saque.

Para información de los señores Castillo y Sáez —pues tal vez no lo sepan y conviene tomen buena nota- de la Introducción a la Paleografía y Diplomática General, en poco más de un año se han vendido cerca de 5.000 ejemplares, y las recensiones que de esta obra se han hecho, especialmente en el extranjero, las que yo conozco, han sido altamente positivas y elogiosas.

Lamento que los "sedicentes" descubridores, promotores y renovadores de la Paleografía actual, por haberles eliminado del título de su colaboración el término "social" y aparecer como título definitivo: "Paleografía e 
historia de la cultura escrita: Del signo a lo escrito", hayan puesto el grito en el cielo, sin tener en cuenta que la Introducción a la Paleografía..., como indica su nombre, es un libro manual e introductorio de Paleografía y Diplomática sin adjetivos, escrito para universitarios que se acercan por primera vez a estas disciplinas.

Pero es todavía más lamentable que me tilden y acusen a mi y a la obra de conjunto, recién publicada, como la representación de la Paleografía descriptiva, tradicional y positivista, seguramente por no haber seguido en nuestra labor docente, investigadora y publicista -que en modo alguno se ciñe a la Paleografía- los luminosos principios doctrinales y valiosas orientaciones de los dos profesores de Alcalá y, sobre todo, «por haber hecho caso omiso - así lo expresan- de las situaciones sociales y culturales a los que responden (las escrituras y lo escrito) y de los que son testimonio" (Scrittura e Civiltà, p. 443). ¿ Es que en la escritura - pregunto yo- sólo subyacen aspectos sociales y culturales?

Quiero agradecer públicamente a los profesores Castillo y Sáez el calificativo que me aplican en cuanto "editor-coordinador" extensible al trabajo de los 12 profesores "coautores", por considerarnos "paleógrafos tradicionales" $y$, también, por la gran propaganda y reconocimiento que nos han hecho con la publicación de su crítica censora - sin duda involuntaria e inconscientemente- no sólo en las Universidades españolas sino también en las europeas e hispanoamericanas.

Lo importante respecto a los profesionales, ya se trate de jueces, políticos, profesores, atletas, toreros, futbolistas, etc., es que efectivamente sean «profesionales" y «maestros", y lo accidental y accesorio es que sean «tradicionales", "modernos» o "ultramodernos». Si no se es "paleógrafo profesional» - $-\mathrm{y}$ esto se detecta en la enseñanza y en las publicaciones dotadas de peso específico, rigor científico-técnico y de validez universal en el campo del saber crítico y de cara a la formación integral del alumnado universitario- no creo que nos vayan a reconocer y dar tal título, por dedicarnos a lo social, antropológico, psico-pedagógico y cultural de la escritura, sino por descubrir, profundizar y exponer los valores fundamentales y de mayor peso científico-critico subsistentes en todo escrito.

La historia de las ideologías y mentalidades, del alfabetismo, de las situaciones sociales y culturales de los pueblos, el aspecto psico-pedagógico, social e interrenacional o publicista de la escritura y de otros muchos aspectos y facetas interesantes, de los que no nos hablan los señores Castillo y Sáez, en modo alguno deben excluirse a la hora de leer, fijar el texto, interpretarlo y valorarlo, y ningún profesor de Paleografía normalmente los omite, pero siempre dando a cada una de estas facetas el rango que le co- 
rresponde dentro de un baremo valorativo, razonable desde el punto de vista científico y pedagógico-docente.

Desde hace años - cuando todavía eran tiernos infantes los dos profesores de la Universidad de Alcalá- aprendí de mis maestros y profesores: Mallon, Battelli, Grissar, Ravikauskas, Blet, Cencetti, Kirschbaum, N. del Re, Stickler, Frenz, Schmidt, Canart, Millares Carlo, F. Marcos Rodríguez, Paoli, Bascapè,..., a distinguir entre Paleografía y Diplomática científicas con sus ciencias afines, y «pseudopaleografía-diplomática" o "Palaeography light from antiquity", como algunos, con gracia, la llaman.

Ninguno de los profesores citados subestimó lo "social» e «interrenacional» de la escritura y de lo escrito, si bien todos ellos dieron preferencia a los aspectos filológicos, lingüísticos, históricos, jurídicos y artísticos y, sobre todo, a los «paleográficos» y «diplomáticos» por considerarlos fundamentales.

Qué quieren los señores Sáez y Castillo ¿qué abandone la línea de quienes tuve y sigo teniendo por auténticos maestros para pasarme a la suya por considerarla superior e iluminadora? Hasta ahora las explicaciones, doctrina, método y técnicas de la «nueva paleografia», que ellos con tanta insistencia proclaman, no me han convencido; expónganlos con claridad y altura científica de forma que aun los menos dotados podamos entender lo que hoy por hoy nos ha parecido superficial, inconsistente y de escaso peso científico. Háganlo, por favor, porque aunque no estemos de acuerdo con lo que escriban y defiendan, respetaremos sus opiniones, puesto que creemos en la libertad de palabra y de pensamiento. Más aún, estamos dispuestos, no a morir —como decía Voltaire - por defender el derecho a decir y escribir, pero sí a aprender, siempre que se trate de auténticas teorías y postulados científicos y no de simples refritos y frases grandilocuentes y descontextualizadas que, por lo general, suenan a disco roto 0 , al menos, rayado, aunque procedan de Bourdieu, McKenzie, Cohen, $\mathrm{Pe}$ trucci, Cavallo, Cardona, Chartier, Hébrard, Duglio, Vovelle, Giner, Haskins..., a quienes admiro y valoro, sobre todo como especialistas en historia de la cultura y civilización y expertos en ideologías y mentalidades. Todos ellos son magníficos tratadistas de sociología, antropología, pedagogía, historia del pensamiento social y político y del alfabetismo, pero a casi ninguno lo considero maestro de Ciencias y Técnicas Historiográficas y disciplinas afines.

Es cierto que varios de los autores citados y algunos otros, que omito en gracia a la brevedad, se han fijado directamente en la escritura y lo escrito en su integridad y en cuanto fenómeno socio-cultural inserto dentro de una sociedad, civilización y ambiente concreto y cambiante, y todos ellos inci- 
den en la transmisión visual y planificación gráfica de los pensamientos, palabras, ideas, actos, mensajes, normas, etc., servidas por este medio simbólico-gráfico, porque en todo escrito subyace determinada intencionalidad, uno o múltiples receptores activos y pasivos, con mayor o menor grado de alfabetización y capacidad intelectual y cultural, y una serie de circunstancias y factores circundantes de carácter histórico, social, político, jurídico-administrativo, lingüistico..., que convierten a la escritura y a su historia en un interesante hecho y fenómeno histórico en si mismo, con enormes repercusiones en cuanto signo y motor de progreso y desarrollo intelectual, científico, económico, informativo, artístico y psicopedagógico. Sin embargo da la casualidad de que en los estudios y publicaciones que ellos nos ofrecen, predomina la "paleografía descriptiva y de análisis" -que no soportan los dos profesores de Alcalá- sobre la sociológica, antropológica y la de usos activos y pasivos de la misma y aun sobre la relacionada con la historia de las mentalidades y de los niveles y ambiente cultural de la escritura y del mensaje o mensajes que nos transmite. También los historiadores, filólogos, juristas, lingüistas, documentalistas, archiveros, grafólogos, epigrafistas, ópticos, químicos..., se han ocupado de la escritura y de lo escrito, en muchos casos con aportaciones importantes en nuestro campo y para nuestros estudios paleográficos, pero siempre indirectamente y con fines más lingüisticos, históricos, archivísticos, jurídicos e institucionales o bioquímicos que paleográticos.

Si la base del lenguaje simbólico-alfabético escrito, formada por letras, signos y simbolos, son las palabras, y éstas, a su vez, el soporte de las ideas, no se empeñen con fervor caudillista, quienes militan en la «nouvelle Paleographie" y tan denodadamente trabajan por una disciplina que abunda en el "rovesciamento" - supongo que del método y de la Paleografía científica- en descalificar a los demás y, por favor, no digan que yo soy inmovilista y que me apego a las posiciones estáticas y anticuadas de la vieja Paleografía de corte descriptivo (a.c., p. 441)

¿A qué Paleografía se aferran los señores Sáez y Castillo? Nuestras disciplinas: Paleografía, Diplomática, Epigrafia, Cronología, Sigilografia, Codicología, Historia de las fuentes escritas, Archivística, Ecdótica, Heurística, Documentación, Historia de la miniatura, de la encuadernación y del arte de las piezas escritas, encuadradas hoy en el área de las Ciencias y Técnicas Historiográficas y en las facultades de Humanidades, forman parte del organigrama disciplinar universitario español y se imparten en las Facultades de Letras, Geografía e Historia, Lengua y Literatura, Filología clásica, Biblioteconomía y Documentación, etc. con marcada orientación a la formación integral del alumnado que aspira a obtener los conocimientos específicos y el título de filólogo, lingüista, archivero, historiador, documenta- 
lista, grafólogo o historiador del arte. A todos estos alumnos y al profesorado de dichas especialidades les importan muy poco los aspectos sociales, psicopedagógicos, etnológicos, antropológicos, ideológicos y aun culturales de la escritura y de lo escrito que, en último término, corresponden a otras licenciaturas y especialidades. Con frecuencia, el discurso de quienes subliman en exceso tales aspectos incurre -en expresión italiana- para unos en un «bel dire» o un "bel fare» y, para otros, en «belline sfumature», más aparentes que reales.

Ningún profesor de universidad que se precie de serlo $-\mathrm{y}$ yo personalmente me incluyo en el grupo de quienes ejercen su oficio y profesión con dignidad - puede adoptar hoy una actitud inmovilista ante la investigación y docencia de cualquier disciplina universitaria, siempre en constante renovación y, menos, rechazar o sentir temor ante los cambios inevitables y de todo punto necesarios en los estudios en torno a la Paleografía y a su objeto directo: la escritura y lo escrito, siempre que dichos cambios sean positivos y supongan para la ciencia renovación y progreso, y no mero retoque de maquillaje superficial e intrascendente, sin que sea preciso romper con el proceso y desarrollo evolutivo de una disciplina científica con larga historia y significado. La Paleografía, si quiere subsistir como ciencia autónoma e interfacultativa, debe ampliar su campo y objetivos específicos y, sobre todo, profundizar en ellos, aparte de incorporar a su estudio, enseñanza y aprendizaje nuevos sistemas y las tecnologías más avanzadas y punteras.

La Universidad española, los planes de estudio y la enseñanza universitaria, por lo que a Letras y estudios humanísticos se refiere, pasan por una profunda crisis. Este "rompecabezas", enloquecedor para profesores y alumnos, se agrava aún más cuando cada docente enseña y diserta, bien a su antojo, sea válida o no su enseñanza, bien de forma inconexa y sin ningún tipo de rigor científico, bien conforme a los escasos créditos y tiempos que se le asignan. Puede llegar el momento - yo al menos así lo espero- que la sensatez y el orden académico-docente se restablezcan, y entonces ¿qué pasará, si nos empeñamos en reducir la enseñanza e investigación de la Paleografía y de su objetivo primario: la escritura y lo escrito, a un único aspecto: “lo social», o a algunos más, pero secundarios y propios de otras especialidades y Facultades?

Los docentes actuales y venideros de la Paleografía y Diplomática y ciencias afines, si no entramos en razón y seguimos, como pretenden los profesores Sáez y Castillo, por la peligrosa senda del abandono de lo más sustantivo y valioso de nuestras disciplinas y las desvinculamos del organigrama oficial al que éstas pertenecen, podemos convertirnos en enterradores de las mismas y no sería raro que hasta consiguiésemos 
que enseñanzas y estudios tan interesantes desde distintos puntos de vista, terminasen - para desgracia del saber y de la cultura- en el cesto de los papeles.

La honestidad personal e intelectual de cualquier profesor de Universidad - y con esto termino- está o debería estar por encima de su maestría, sabiduría y erudición, y nadie, ni siquiera los docentes de Paleografía y Diplomática de la Universidad de Alcalá de Henares, tienen que impacientarse y perder los nervios porque otros colegas y compañeros, más respetuosos que ellos, sostengan posturas y opiniones distintas en materias opinables, máxime si aquéllas gozan ya de prestigio internacional y de fundamentación científica, y, de cara a la formación científico-técnica del alumnado, tales enseñanzas resultan operativas y eficaces.

Ángel Riesco TERRERO Universidad Complutense 